\title{
TTR
}

Traduction, terminologie, re?daction

\section{Process-Oriented Research into Translation and Implications for Translation Teaching}

\section{Wolfgang Lörscher}

Volume 5, numéro 1, 1er semestre 1992

La pédagogie de la traduction : questions actuelles (1) et Miscellanées traductologiques

URI : https://id.erudit.org/iderudit/037110ar

DOI : https://doi.org/10.7202/037110ar

Aller au sommaire du numéro

Éditeur(s)

Association canadienne de traductologie

ISSN

0835-8443 (imprimé)

1708-2188 (numérique)

Découvrir la revue

Citer cet article

Lörscher, W. (1992). Process-Oriented Research into Translation and Implications for Translation Teaching. TTR, 5(1), 145-161.

https://doi.org/10.7202/037110ar d'utilisation que vous pouvez consulter en ligne. 


\section{Process-oriented research into translation and implications for translation teaching}

\section{Wolfgang Lörscher}

O. Until very recently, translation theory has been primarily concerned with two phenomena: with translation as a product and with translation competence (Lörscher, 1991, 1 ff.).

- Translation as a product, i.e. a written text in a targetlanguage (TL) as the result of a translation process, has traditionally been described and analysed by a comparison with the respective source-language (SL) text. The relation between the SL text and the TL text has been dealt with in a large number of different and highly theoretical models of equivalence. By and large, these models have been prescriptive rather than descriptive and of very limited use to the practical translator.

- Translation theory was mainly competence-oriented and focused on (professional) translators' internalised knowledge. The models of translation were theoretical and speculative rather than empirical and concentrated on idealizations rather than on actually occurring data.

As a consequence of translation theory being product- and competence-oriented, hardly any attention has been given to the process by which a translation is produced, and to translators' actual performance. This narrowing of the object and of the dimensions in 
which it is investigated have only recently been realized to be a deficit. As a result, a new, process-oriented, performance-analytical discipline within translation studies has developed (cf. Gerloff, 1988; Jääskeläinen, 1990; Krings, 1986; Lörscher, 1991; Séguinot, 1989; Tirkkonen-Condit, 1991).

The empirical investigation of the translation process seems to be especially important for three reasons:

1. As far as the psycholinguistic investigation of translation is concerned, it can be expected that only on the basis of empirical studies of translation performance using a process-analytical approach can hypotheses on what goes on in the translator's head be formed. Thus, light could be shed on translation as a psychological process which is still largely unknown and uninvestigated.

2. As far as psycholinguistic investigation in general is concerned, it can be expected that empirical studies of translation performance will yield general insights into language processing, about aspects of the mental processes of speech reception and speech production and about the mental strategies employed by the language user.

3. As far as the teaching of translation is concerned, it should be possible to make use of knowledge of the translation process for teaching translation. If certain translation strategies turn out to be successful, it might be worth considering teaching these strategies in one way or another. This aspect will be dealt with in more detail in the final section of this paper.

My own research, and thus the considerations made in this paper, can be located within this newly established field. They are based on a research project which I have been carrying out since 1983. The aim of this project is to analyze psycholinguistically translation performance as contained in a corpus of orally produced translations from German into English and vice versa. This is done in order to reconstruct translation strategies. These underlie translation performance, operate within the translation process, and are thus not open to direct inspection. In the first stage of the project, translation 
processes of advanced foreign language learners were investigated. The results yielded are contained in my monograph Translation Performance, Translation Process, and Translation Strategies. A Psycholinguistic Investigation (Tübingen, 1991). The second stage of the project, in which professional translators' and, later on, bilingual children's translation processes are analyzed, is in progress (Lörscher in preparation).

I. It is an obvious fact that translation competence, as possessed by professional translators, is the result of a developmental process that is never final. The process is based on a predisposition to translate which every individual is endowed with. This innate predisposition is not controversial in translation theory. What is most controversial, however, is the way translation competence develops from an individual's innate predisposition. At the moment two highly controversial developmental models exist. One was proposed by Harris (1977) and Harris/Sherwood (1978) the other by Toury (1986).

Harris and Sherwood investigated "natural translation", i.e. "... the translation done by bilinguals in everyday circumstances and without special training for it." The authors maintain that in addition to their competence in the two languages involved, bilinguals possess a third competence, that of translating between the two languages. Harris and Sherwood emphasize that translation competence unfolds itself parallel to the development of bilingualism, and that the degree of translation competence increases automatically to the extent to which a child's ability to use the two languages involved develops.

The second developmental model of translation competence was proposed by Toury. He agrees with Harris and Sherwood about an innate human predisposition to translate and considers it to be "co-extensive with bilingualism." The differences between the two concepts become evident when Toury points out that translation competence does not develop quasi-automatically and parallel to the development of a child's bilingualism. Bilingualism is considered to be a necessary, but not a sufficient precondition for the development of translation competence. In addition to an individual's bilingual or quasi-bilingual competence an interlingual or transfer competence must be built up. Apart from other possible but hitherto unknown factors, it 
comprises the individual's ability to transfer texts equivalently on various levels according to a given purpose/aim and with regard to sense, communicative function(s), style, text type, and/or other factors; or to deliberately violate postulates of equivalence for a certain purpose (Hönig/Kußmaul, 1982; Reiß/Vermeer, 1984).

II. My research into translation processes is founded on the hypothesis that every individual who has a command of two or more languages (even with various degrees of proficiency) also possesses a rudimentary ability to mediate between these languages. On the one hand, this hypothetical construct takes a medial position between Harris/Sherwood and Toury, on the other hand, it goes beyond Harris/Sherwood and Toury in three important aspects:

1. The question as to whether translation competence is a natural phenomenon which comes into being and develops automatically and parallel to an individual's bilingualism can only be answered in terms of the concept of translation which one adopts. In translation theory, it is customary to define translation as a text-based activity which, with respect to the purpose of the translation and its addressees, aims at rendering a source-language text into a target-language text so that equivalence of sense and/or function and/or style and/or text type, etc., will be realized in an optimal way for the various levels of the text (Reiß/Vermeer 1984). If one adopts such a concept of translation, Harris and Sherwood's hypothesis must obviously be questioned. The data which the authors discuss suggest that their subjects produced approximate mediations of sense rather than translations which correspond to the definitional criteria mentioned.

Those elementary forms of mediation of sense which can be observed in bilingual children at a very early age are neither considered to be translations by translation theory nor are they given any attention by translation theorists. The main reason for this may be that translation theory focusses on professional translators and their highly developed translation competence.

With the aim of my research in mind, i.e. a psycholinguistic analysis of the translation process, I think it is sensible to subsume bilingual children's mediations under the heading of translation. It is 
only after a comparison of the products and the mental processes as they are to be found in or can be reconstructed from bilingual children's and professional translators' performance that it would be possible for a model of translation competence with either a wide or a narrow concept of translation to rationally be construed.

2. In both Toury's and Harris/Sherwood's developmental model, bilingualism is considered to be a crucial precondition for translating or is taken to comprise the ability to translate (i.e. in natural translation). Real bilingualism, i.e. an absolutely equal degree of availability of two languages in any situation and for any information to be communicated, probably only exists in approximations.

This is equally true for professional translators. As a rule, their competence in one language is higher than in the other. Furthermore, there are considerable differences among professional translators with respect to their competence in the languages involved.

Since bilingualism and bilingual competence can only be achieved approximately, the logical consequence is to hypothesize as well a rudimentary ability to mediate information between languages for people who are in possession of a mother tongue and an interlanguage (Selinker, 1972), and to consider their mediations as translations in a broad sense. This seems to be justified because the transition from an interlanguage to a fully developed second language - as far as this can be achieved by learners - is a continuum rather than a fixed boundary.

3. The elementary forms of mediation which have been outlined occur in real mediating situations, in which communication between a source-language text sender and a target-language text receiver is established via a mediator. The data for my research were not collected in real mediating situations. First, there was no explicit addressee for whom the translations had been performed, although in the minds of the test subjects the test leader might have played this role. Second, both the subjects and the implicit addressee of the translation (the test leader) share the same languages involved in the translations. There was no language barrier which would have made translations necessary to establish communication. The purpose of the translations for the subjects was rather to externalize data on the translation process, 
and for the test leader to collect these data. Thus communication in the translations of my corpus resembles didactic communication in the foreign language classroom which I have analyzed elsewhere (Lörscher, 1983). In spite of the artificial element inherent in the translational communications and the situations in which they were produced, the modes of realization of the subjects' evident rudimentary ability to mediate will be categorized as translations. From a process-analytical perspective this seems to be sensible because it is still unknown whether translation processes in real mediating situations are different - in detail or in principle - from translation processes in artificial mediating situations. A distinction between these phenomena would only be justified if a comparison of the data collected in these two kinds of mediating situations revealed significant differences.

As a result of the three arguments outlined, it can be pointed out that an individual's elementary ability to mediate leads to performance products which are to be classified as translations. As soon as an individual has an even partial command of two or more languages, elementary mediations between them become possible. The rudimentary ability to mediate and its modes of realization function irrespective of the genuine nature of the mediating situation and irrespective of the naturalness of its communication.

III. The existence of an innate rudimentary ability to mediate and of its realization in elementary translations cannot be proved in the strict positivist sense. But it seems highly plausible in the light of the following two considerations:

i. The rudimentary ability to mediate as realized in elementary translations can be considered a special case of at least two universal innate abilities of the human intellect: that of categorizing and that of comparing, of differentiating similarities and dissimilarities. Both these abilities, which also underlie any natural linguistic competence, make it possible for the individual to express sense and/or connections of signs in different ways. The mediations of sense and/or signs can occur within the verbal sphere, between the verbal and the nonverbal spheres and between different nonverbal spheres. As soon as an individual has at least partially acquired modes of verbal and/or nonverbal behaviour, rudimentary mediations between them are possible. As a matter of fact 
it can be observed that a child who has partially acquired his or her mother tongue as well as the meaning and use of gestures, facial expressions, etc. is able to express information available in a verbal code by means of gestures or facial expressions, and vice versa. Admittedly, these mediations differ considerably from those made by experts (e.g. professional mimes) as regards range, quality, and possibly other criteria, but nonetheless they are considered to be mediations even though they are imperfect ones.

ii. The training of students for translation and interpretation never starts from scratch but builds on the skills which the students already possess. These may have been acquired in the foreign language classroom, but they in turn build on even more basic mediating skills. The starting-point of an individual's rudimentary ability to mediate between two or more languages and its realization in elementary translations is probably marked by the beginning of the acquisition process of a second language. During this process - especially when it takes place in the classroom - a widespread phenomenon can be observed: learners often systematically relapse into their mother tongue. It functions like a filter through which the foreign language is received and produced. According to Ringbom (1985) it is a generally accepted principle that L2-learners constantly seek to facilitate their difficult task by making use of all those parts of their previous knowledge which they consider (potentially) relevant. Their previous linguistic knowledge consists of both what they already know about the target-language and of their knowledge of their L1 and possible other languages. The learners' recourse to their L1 knowledge and the learners' relating it to their relevant L2 knowledge in order to augment and develop the latter represents a case of a uni-directional mediation of information.

There is, furthermore, a phenomenon of importance which occurs primarily during the initial phase of foreign language learning at school: it is the learners' translation of foreign language material which they have received, in order to be able to (better) decode it; or, in foreign language text production, it is the learners' production of an interim native-language text which they will then translate into the foreign language. The latter is often done because directly producing a foreign language text is often considered more difficult than producing it via a translation. 
It is no wonder that the two kinds of mediation of information just mentioned and the products which they yield are not considered translations in translation theory. They are phenomena which do not occur in professional translating and therefore the models of translation theory either cannot cope with them at all or cannot cope with them satisfactorily (Lörscher, 1989). For the reasons mentioned, however, I think it is sensible to investigate them when one aims at analyzing translation processes or when one aims at finding out how translation competence develops.

IV. As I pointed out earlier, the rudimentary ability to mediate is the basis of all translating and thus underlies the elementary mediations done by bilingual children as well as the translations performed by professionals and by foreign language learners. In addition to many more differences between the translations of the three groups of mediators mentioned, the process-oriented approach to the translations is of special importance here because it is an essential characteristic feature of the various developmental stages of translation competence.

As the data I elicited show, subjects can approach translations in basically two different ways: sign-/form-oriented or sense-oriented (Lörscher, 1991).

In sign- or form-oriented translating, subjects transfer source-language text segments by focussing on their forms (=succession of signs) and by replacing them by target-language forms. This transfer of forms/signs is brought about without recourse to the sense of the two text segments involved.

Substitutions of signs mainly occur in the lexical domain and result from vocabulary equations which the subjects have learned in foreign language lessons at school or at the university. Above all, decontextualized and purely sign-oriented vocabulary learning, which even today is rather widespread, forms and provides a large number of purely surface-structure lexeme equations, such as German "Entwicklung" is English "development", or "country" in English means "Land" in German. 
When a subject is faced with an SL text segment as part of a lexeme equation stored in memory, the TL text segment as the second part of the lexeme equation may become available to the subject through an automatic association process.

In my corpus of translations produced by foreign language learners, a large number of indicators of sign-oriented translating can be detected, which are discussed in detail elsewhere (Lörscher, 1991, pp. 272-274).

As pointed out before, sign-oriented translating is characterized by a recall from memory and a verbalization of TL forms which correspond to the respective SL forms. Sign-oriented translations are mainly brought about by automatic association processes, and employ an inventory of stored surface-structure equations of lexemes. This is represented in diagram 1 :

\section{Diagram 1: Sign-Oriented Translating}

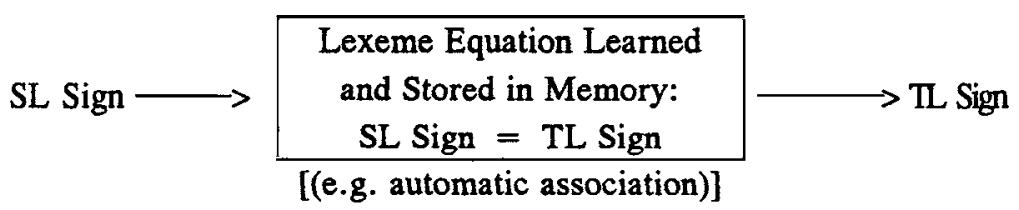

A further possibility of finding target-language text segments which correspond to source-language ones is sense-oriented translating. The sense combined with an SL text segment is made explicit by the translator and thus "separated" from it. On the basis of the sense thus constituted, the translator searches for adequate TL signs. The process of sense-oriented translating can be diagrammatically represented as follows: 


\section{Diagram 2: Sense-Oriented Translating}

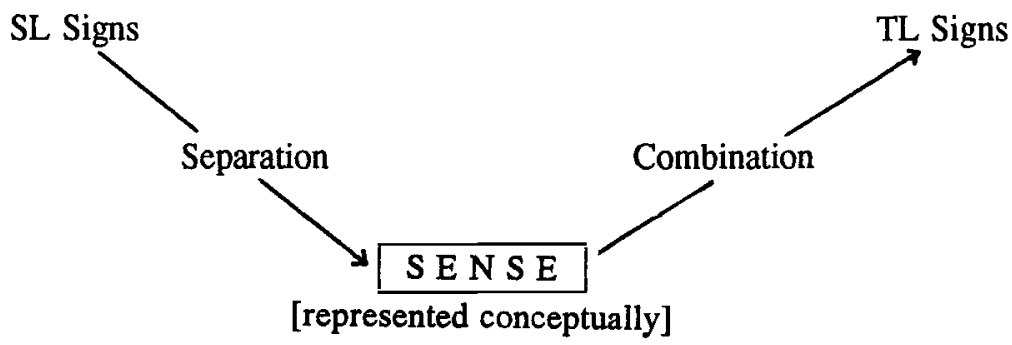

During or after the separation of SL forms from their sense, the subjects try to combine the sense, to the extent to which they have interpreted it, with (a sequence of) TL forms. This requires a process of searching in which situational and contextual factors that determine the range of sense of an SL text segment are taken into account. This again depends on the trarislator's competence and experience in translating and in the two languages involved.

V. The two approaches to translation which have been outlined are like two extremes, between which the concrete translational activities of the subjects range. Neither exclusively sense-oriented nor exclusively sign-oriented procedures can be found in the corpus and probably do not occur in any human translating. Nonetheless, the data clearly show that the foreign language learners tend to produce the translations primarily in a sign-oriented way.

This does not at all exclude the sense-oriented translation of certain text segments. But on the whole, it must be assumed that non-professional translators take a mainly sign-oriented and professional translators a mainly sense-oriented approach to translation. As concerns the foreign language learners four reasons may be responsible for their sign-oriented approach to translation:

a. As already pointed out, it is a widespread view among laymen that a translation is mainly an exchange of signs (words, syntagmas, clauses, and sentences) between two languages. Thus a 
translation would have to focus on the sign inventory of the SL text and reproduce this, in as literal a way as possible, with the signs of the TL. As a matter of fact, this view is strongly supported, if not conditioned, by translation as a form of training and/or testing foreign language competence, which even today is far too often practiced in foreign language classrooms.

b. A further explanation of the apparent dominance of sign-oriented translation is provided by the psycholinguistic minimax strategy discussed by Krings (1986). Both his and my data elicited from foreign language learners clearly suggest that the subjects try to keep the cognitive load as light as possible during their translations. This is in accordance with the principle of economy which applies to mental processes. The subjects generally do not proceed to a deeper level of cognitive processing, which is more abstract and implies a higher cognitive load, before the processing on the higher level has turned out to be unsuccessful or unsatisfactory. But as sign-oriented translating probably goes along with information processing which is, in principle, less complex and/or laborious, it can be expected that the subjects do not proceed to sense-oriented translating before sign-oriented procedures have turned out to be unsuccessful or unsatisfactory. This assumption is supported by the results which the quantitative analysis of my data yielded (Lörscher, 1991).

c. The fact that one of the languages involved in the translations of the foreign language learners is "only" available to them as an interlanguage must be seen in close connection with the preceding explanation. The foreign language reception and production problems represent such a high cognitive load to the subjects that a checking on the sense of the speech they receive and produce is prevented. Thus an important monitor remains largely inactive.

d. The above-mentioned artificiality of the mediating situation and the unnaturalness of the communication within it are not very likely to favour sense-oriented but rather form-oriented translating. The great majority of the foreign language learners had never been in a genuine mediating situation and made communication between an SL sender and a TL receiver possible or easier. They lack the experience of being 
responsible for an addressee's understanding the sense of an SL text, which certainly does not hinder sign-oriented translating.

VI. The considerations made sofar lead to the following theses: The rudimentary mediating competence and its forms of realization in elementary translations, as can be observed with children in the sense of a natural translation, are characterized by a sense-oriented approach to translation. The rudimentary ability to mediate is based on a bilingual competence and unfolds itself in real mediating situations for purposes of making communication possible or easier. The mediations performed by foreign language learners are characterized by primarily form-/sign-oriented procedures. They are made possible by a mother tongue competence and a partial competence in a foreign language. The mediations normally take place in artificial mediating situations. They neither make communication possible nor easier, but serve didactic purposes. Professional translators take a primarily sense-oriented approach to translation. Their developed mediating competence is based on a quasi-bilingual competence and unfolds itself in real mediating situations in which genuine communication takes place. The development of an individual's rudimentary ability to mediate towards translation competence, as professional translators possess it in its elaborated realizations and non-professional translators in its largely deficient forms, is schematically represented in diagram 3 : 
Diagram 3: The development of the rudimentary ability to mediate towards translation competence

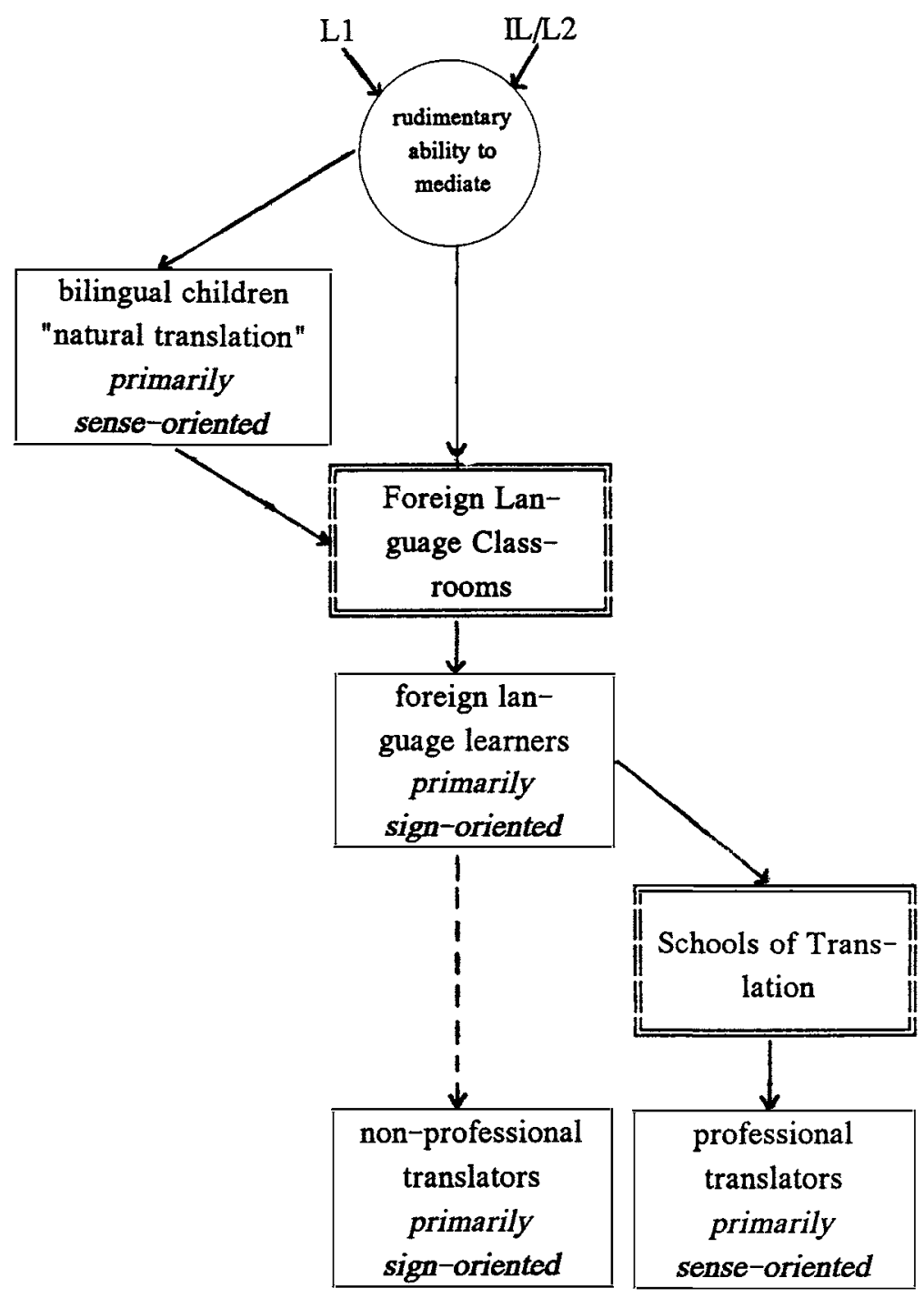


The rudimentary mediating competence in its largely sense-oriented forms manifests itself in bilingual children's natural translation. In the foreign language classroom, in which translation is taken out of its communicative dimension and functionalized for the training and testing of foreign language skills, the rudimentary ability to mediate undergoes a decisive deformation. It is largely reduced to the level of the signs. This is documented in the translations of the foreign language learners and generally remains with non-professional translators. It is the task of the schools of translation to reverse this deformation. The professionals whom they train approach translations in a primarily sense-oriented way and thus adopt procedures used by bilingual children.

With regard to their approach to translation, bilingual children and professional translators have thus more in common with each other than with foreign language leamers. It is therefore an urgent task, especially for the schools, to search for possibilities of developing the rudimentary mediating competence towards an elaborated translation competence. By maintaining an apparently inadequate concept and view of translation, this development has far too often been seriously hindered.

VII. The questions which obviously suggest themselves here are what steps can be taken to favour the development from a subject's rudimentary ability to mediate towards translation competence, and what process-oriented investigations can contribute to translation teaching. Although these two questions cannot yet be answered finally, I would like to outline some of my thoughts on these problems.

As concerns the first question, I think it is essential to confront foreign language learners and especially teachers with the shortcomings of and the gross translation errors often caused by the use of purely sign-oriented procedures. As a first therapeutic measure, subjects should be sensitized to the deficits and inadequacies of those translations which are mainly produced by an exchange of signs. In the data elicited by me and by other scholars, numerous examples of such inadequacies can be found. Since the foreign language learners generally approach their translations in a sign-oriented way, the monitor which checks on the sense of their translations remains largely inactive. As a result, target-language texts are produced which are neither equivalent in sense 
to the respective source-language texts nor grammatically or stylistically acceptable texts by themselves. This is even true of texts in the subjects' mother tongue. They, too, often reveal the deficits just mentioned. Obviously, this is not caused by lack of competence. When the subjects were confronted with their own translations some time after the translation task, they could hardly believe that they had produced texts in their native language with such a high degree of grammatical and stylistic errors. The subjects would certainly not have made these errors if their task had only been to produce a text with a certain meaning in their mother tongue. The deficits in the target-language texts are mainly caused by the task of translating and the subjects' sign-oriented approach to translation which prevents any checking on the sense of the target-language text produced. Making the foreign language learners and teachers aware of these deficits and making them constantly check on the sense of the texts they produce in their translations may be a first step towards sense-oriented translating.

The second question, what process-oriented investigations can contribute to translation teaching, can only be answered in a very preliminary and tentative way. To my mind, the main, if admittedly modest, merit of these investigations is that they have helped to locate, describe, and explain deficits in non-professional translating and have thus contributed to making us aware of aspects of the structure and of the complexities of translation.

To date, process-oriented research into translation has been purely descriptive, not prescriptive. Its principal aim has been to find out what actually goes on in the translator's head, i.e. how s/he translates, not how $\mathrm{s} / \mathrm{he}$ should translate. The investigation of translation strategies has been carried out from the perspective of the subjects as hypothetically reconstructed by the analyst (Lörscher 1991). Thus, translation strategies are successful to the extent to which the subjects succeed in bringing about what to them are solutions to translation problems.

It is evident that what the subjects consider to be successful and what the analyst does often do not coincide. It is just as evident and can be documented empirically that subjects more often than not find target-language text segments which they consider to be solutions to 
problems but which apparently are translation errors. Nonetheless, such strategies are considered successful in view of the concept of success used in process-oriented investigations. It would certainly be interesting and informative to compare what the subjects investigated consider to be success in their translation with what professional translators and/or bilingual informants would consider to be success. In this way, norms for evaluating translation strategies and ways of teaching successful strategies, in one way or other, could be developed. Although this is hardly more than a desideratum and goes beyond the scope of most of the process-oriented investigations, it is one, if not the most urgent, desideratum of research into translation processes at present.

\section{University of Greifswald at Neubrandenburg, Germany}

\section{References}

GERVER, D. and Sinaiko, W.H., eds. (1978). Language Interpretation and Communication. New York.

HARRIS, B. (1977). "The importance of natural translation." Working Papers on Bilingualism, 12, pp. 96-114.

HARRIS, B. and Sherwood, B. (1978). "Translation as an innate skill," in Gerver and Sinaiko (1978), pp. 155-170.

HÖNIG, H.G. and Kußmaul, P. (1982). Strategie der Übersetzung. Ein Lehr- und Arbeitsbuch. Tübingen.

GERLOFF, P.A. (1988). From French to English: A Look at the Translation Process in Students, Bilinguals, and Professional Translators. Mimeo; Harvard University.

JÄÄSKELÄINEN, R.H. (1990). Features of Successful Translation Processes: A Think-Aloud Protocol Study. Mimeo; University of Joensuu, Savonlinna School of Translation Studies. 
KRINGS, H.P. (1986). Was in den Köpfen von Übersetzern vorgeht. Eine empirische Untersuchung der Struktur des Übersetzungs prozesses an fortgeschrittenen Französischlernern. Tübingen.

LÖRSCHER, W. (1983). Linguistische Beschreibung und Analyse von Fremdsprachenunterricht als Diskurs. Tübingen.

(1989). "Models of the translation process: claim and reality." Target, I(1), pp. 43-68.

(1991). Translation Performance, Translation Process, and Translation Strategies. A Psycholinguistic Investigation. Tübingen.

(in preparation). Translation as Process. An Empirical Investigation into the Translation Process of Professionals, Bilinguals, and Foreign Language Learners.

REIB, K. and Vermeer, H.J. (1984). Grundlegung einer allgemeinen Translationstheorie. Tübingen.

RINGBOM, H., ed. (1985). Foreign Language Learning and Bilingualism. Åbo.

SÉGUINOT, C., ed. (1989). The Translation Process. Toronto.

SELINKER, L. (1972) "Interlanguage," International Review of Applied Linguistics in Language Teaching, 10, pp. 219-231.

TIRKKONEN-CONDIT, S., ed. (1991). Empirical Research in Translation and Intercultural Studies. Tübingen.

TOURY, G. (1986). "Natural Translation and the Making of a Native Translator." TEXTconTEXT, 1, pp. 11-29. 